\title{
CDISC SDTM Genetic Region of Interest Type Terminology
}

National Cancer Institute

\section{Source}

National Cancer Institute. CDISC SDTM Genetic Region of Interest Type Terminology. NCI Thesaurus. Code C132317.

Terminology associated with the genetic region of interest type codelist of the Clinical Data Interchange Standards Consortium (CDISC) Study Data Tabulation Model (SDT M). 